\section{EMBRYRIDDLE}

Aeronautical University

SCHOLARLY COMMONS
Journal of Aviation/Aerospace

Education \& Research

Volume 14

Number 1 JAAER Fall 2004

Article 1

Fall 2004

\title{
A Comparative Study of Collegiate Aviation Students and Business Students Related to Myers-Briggs Type Indicator Preferences
}

Mary N. Kutz

David B. Carmichael

Mahmood Shandiz

Dovie M. Brown

Follow this and additional works at: https://commons.erau.edu/jaaer

\section{Scholarly Commons Citation}

Kutz, M. N., Carmichael, D. B., Shandiz, M., \& Brown, D. M. (2004). A Comparative Study of Collegiate Aviation Students and Business Students Related to Myers-Briggs Type Indicator Preferences. Journal of Aviation/Aerospace Education \& Research, 14(1). https://doi.org/10.15394/jaaer.2004.1532

This Article is brought to you for free and open access by the Journals at Scholarly Commons. It has been accepted for inclusion in Journal of Aviation/Aerospace Education \& Research by an authorized administrator of Scholarly Commons. For more information, please contact commons@erau.edu. 


\title{
A COMPARATIVE STUDY OF COLLEGLATE AVIATION STUDENTS AND BUSINESS STUDENTS RELATED TO MYERS-BRIGGS TYPE INDICATOR PREFERENCES
}

\author{
Is There a Significant Difference Between Preferences \\ of Students Who Choose Aviation and Students \\ Who Choose Business as A Major?
}

Mary N. Kutz, David B. Carmichael, Mahmood Shandiz, and Dovie M. Brown

\begin{abstract}
There has been limited research to date that addresses the difference, if any, between students who choose the various fields of aviation as a major, and those who choose other majors, particularly business. This study utilizes the Myers-Briggs Type Indicator (MBTI) to compare preferences of aviation majors to business majors because of its unique characteristics and its noted lack of use in the aviation arena. The findings of the study revealed that there are no significant differences between business and aviation students in the Myers-Briggs Type Indicators except in the way they orient themselves in the environment (Judging and Perceiving). These findings are a reminder to teachers of aviation students that classroom structure should balance discussion, practice skills, fun and other activities with learning objectives to accommodate the dominant styles of aviation learners. On the other hand, the predominant Judging style of business students would demand that classroom discussion be somewhat limited in order to meet specific learning goals. Maintaining a balance of teaching style is important both for the teacher and the student in reducing the discomfort of the teacher operating outside a preferred style and eliminating the mental stress of the student attempting to learn new material while using an auxiliary type.
\end{abstract}

\section{INTRODUCTION}

\section{Background}

Although there has been a significant amount of research pertaining to student preferences in a variety of fields, very little research speaks to the difference, if any, between students who choose the various fields of aviation as a major, and those who choose other majors, particularly business. Those differences provide a fertile field of inquiry in that they have significant implications for faculty who teach in these fields.

The complexities of the $21^{\text {st }}$ century present unique challenges to all educators to ensure the needs of the community are met. This is especially significant in the aviation community due to the natural volatility of the industry and the events of $9 / 11$. In order to more effectively educate future aviation leaders, it would prove useful to understand the relationships of different personality or psychological types/preferences of current aviation students and compare those types to students in other professional environments to determine not only difference in type, but also whether or not students differ significantly in their communication and learning preferences.

\section{Purpose of the Study}

The purpose of this study was to identify the MyersBriggs Type Indicator (MBTI) psychological preferences of business students at Oklahoma City University and aviation students of Oklahoma State University to provide a better understanding of where these students (1) prefer to focus their attention (Introversion or Extraversion); (2) the way they prefer to take in information (Sensing or Intuition); (3) the way they prefer to make decisions (Thinking or Feeling); and (4) how they orient themselves to their environment (Judging or Perceiving). The data could further provide a baseline to track changes in those dimensions as students 
progress into their careers. The study begins the process of examining aviation student preferences compared to preferences of students in other fields in an effort to add to the body of knowledge used by educators in developing curriculum. The findings of the study could impact faculty teaching styles in business, management, and aviation as well as other fields.

\section{MBTI Instrument and Terms}

The MBTI was the instrument used in this study to differentiate aviation student preferences at a large state research university from business students at the private university. The MBTI was used pecause of its unique characteristics and its limited use thus far in aviation education. The architects of the MBTI state that if people differ systematically in what they perceive and in how they reach conclusions, then it is only reasonable for them to differ correspondingly in their interests, reactions, values, and skills (Briggs Myers, McCauley, Quenk, Hammer, 1998, p. 3). The MBTI postulates dichotomies that are believed to reflect innate psychological or mental dispositions. (Briggs Myers, et. al., 1998, p. 4).

Designed by Katherine $C$. Briggs and Isabel Briggs Myers the MBTI is based on Jung's theory of psychological type and has been used extensively in other fields to study both students and faculty but has yet to be applied extensively to aviation or used to compare students of aviation to students of other fields. The MBTI measures the following preferences: Extraversion/Introversion, Intuition/Sensing, Thinking/Feeling, and Judging/Perceiving. Each of these dichotomies are indicated by a one-letter identifier: $\mathrm{E}$ and I; $\mathrm{N}$ and $\mathrm{S} ; \mathrm{T}$ and $\mathrm{F}$; and $\mathrm{J}$ and $\mathrm{P}$, respectively.

For MBTI purposes, preferences for Extraversion are manifested by orientation to the outer world. People who prefer Extraversion are focused on people and things and are active. They confidently use trial and error, and they scan the environment for stimulation.

People using introverted preferences, on the other hand, are oriented to the inner world. They are focused on ideas and inner impressions. They are reflective and consider deeply before acting. They find stimulation inwardly.

The second dichotomy relates to perceptions of individuals in terms of the way they take in data. People using Sensing perceptions perceive with the five senses. They attend to practical and factual details. They are in touch with physical realities and attend to the present moment. They confine attention to what is said and done and see the little things in everyday life. They attend to stepby-step experience and let the eyes tell the mind.

People using Intuitive perception perceive with memory and associations. They see patterns, meanings and possibilities. They project possibilities for the future. They use imaging, and read between the lines. They look for the big picture. They have hunches, and ideas out of nowhere. They let the mind tell the eyes.

The third dichotomy deals with the way people make judgments or reason. Those reasoning with Thinking use logical analysis utilizing objective and impersonal criteria. They draw cause and effect relationships and are firmminded. They prize logical order, and are skeptical.

People reasoning with Feeling, on the other hand, apply personal priorities. They weigh human values and motives of themselves and others. They are appreciative and value warmth in relationships. They value harmony and are trusting by nature.

The fourth and last MBTI dichotomy deals with attitudes in terms of Judging and Perceiving. People using a Judging attitude use thinking or feeling judgments outwardly. In this mode, people plan and make decisions. They control and regulate what they are dealing with. They are goal oriented and want closure, even when data are incomplete.

People using a Perceiving attitude are using their perceptions outwardly, taking in information and adapting and changing accordingly. They are curious, interested and open-minded. They tend to resist closure to obtain more data. (Lawrence, 1998).

\section{REVIEW OF THE LITERATURE USE OF MBTI IN STUDYING STUDENT AND FACULTY PREFERENCES}

The Myers-Briggs Type Indicator (MBTI) is an instrument that has been used since the $1960 \mathrm{~s}$ in a variety of professions. (Mitchell, 1976; Shank \& Langmeyer, 1994; Simon, 1978). Since that time, it has been one of the most widely utilized inventories for educational and organizational purposes (McCaulley, 1990). "MBTI profiles have been examined with many variables including career preference, learning styles, behavioral patterns, aptitude, motivation, achievement and creativity" (McCaulley, 1990, p. 537).

Otto Kroeger and Janet Thuesen in Type Talk at Work, How the 16 Personality Types Determine Your Success on the Job (1993) provided graphs of the personality types of managers, executives and trainers/educators to show how "very different (indeed nearly opposite)" (p. 397-398) trainers and educators are from the people for whom they provide training and educational services. The educators had eleven times more Feelers than the executives studied. The trainers/educators were heavily $\mathrm{E}$ (73 percent), $\mathrm{N}$ (71 percent), $F$ (38 percent), and $P$ ( 43 percent)-designing and implementing programs for a largely ISTJ work force" (p. 398). 
This understanding of the disparity between preferences of educators and students has prompted research of both students and faculty in a variety of professional fields. Since the early 1960s, the MBTI has been used both for student advisement and career planning as well as in teaching to individualize learning or orient leaming to a specific career field. Universities have even utilized the MBTI in a variety of studies pertinent to academic success.

In 1993 the Vice Chancellor for Student Affairs at the University of Missouri-Columbia suggested that the MBTI, which has been administered to over 4,000 college freshmen on numerous campuses for over a 15-year period, could provide valuable insights for understanding the modern college student. One example cited by Shroeder was that 60 percent of freshmen prefer Sensing over Intuitive orientation which means they prefer to interpret the world only in terms of what they could physically see, hear, touch, taste, or smell (Schroeder, 1993). This could have implications in terms of problems with courses that require conceptual thinking or abstract thinking versus concrete ideas.

\section{Use of MBTI in Specific Career Fields}

Engineering is just one example of many career fields that have been able to utilize type in identifying student preferences and the impact on faculty teaching styles. Numerous studies have been done and numerous articles published on engineering student and engineering faculty preferences. In 1976 McCauley published an article, which was followed by a series of articles addressing the implications of the MBTl in teaching engineering students. In 1983 she co-authored an article with four other researchers entitled "Applications of Psychological Type in Engineering Education" (McCaulley, Godleski, Harrisberger, Sloan, \& Yokomoto, 1983). In 1985 Rodman and Dean of West Virginia University published an article on teaching implications for engineering students based on their study of undergraduates. Felder and Silverman published an article in 1988 that addressed student-learning styles versus engineering faculty teaching styles. In the 1990s a study was done by Thomas which compared engineering student typologies of the 1970s with students of the 90's to determine if there had been significant changes in type over that period to suggest that engineering student learning/teaching methodology based on MBTI data results might be in need of an update (Thomas, 1998). Engineering is just one of many fields which have utilized type research to improve understanding of student and faculty preferences. Use of MBTI in Business

Although there have been numerous uses of the MBTI to study preferences of business managers, executives as well as students and faculty in business, one study was particularly insightful and pertinent to the comparison with aviation students. In 1987 Carland and Carland used the MBTI to do a comparative study of the cognitive styles of business versus non-business students at Western Carolina University. The dominant preferences of the non-business majors tended to be Intuitive, Feeling, Judging while business students preferred Sensing, Feeling, and Judging. The primary difference between the two was the dominant use of the senses by business majors to interpret the world with its corresponding implications for problems with abstract thinking (Carland \& Carland, 1987).

Use of MBTI in Aviation

Although the MBTI has been used extensively in other career fields such as education, engineering, medicine, pharmacy, and many others, its use in aviation has been somewhat limited. Aviation has not been a field that has utilized the MBTI extensively to research student preferences and address the implications of those preferences for faculty members. This study begins that process by not only looking at aviation student MBTI preferences and their implications for learning but by comparing aviation majors to business majors to determine if there are significant differences in the two fields. This is especially important since Aviation Management is one of the specialties one may choose in Aviation Education curriculum and there are strong ties between the two fields.

\section{METHODOLOGY}

Population/Sample

The MBTI Form $M$ was administered to a stratified random sample of 118 aviation management, professional pilot, and technical services students (both graduates and undergraduates) from a population of 178 who were enrolled in selected aviation classes at Oklahoma State University in Stillwater, OSU-Tulsa, and OSU Extension at the Oklahoma Military Department, Oklahoma City. The MBTI was also administered to a sample of 167 business students (both graduates and undergraduates) from a population of 405 at Oklahoma City University. This sample size was considered to be adequate for testing of the hypotheses in this study but the authors did not attempt to generalize the findings beyond the present study. Since the population was limited to students at Oklahoma City University and Oklahoma State University, one cannot safely generalize the results of this study to other colleges and universities.

\section{Data Collection and Analysis}

The instruments were scored and a database established for undergraduates and graduates in each of the four dimensions associated with each type. Scores were maintained using only a numerical identifier not associated with any individual name. The data was then analyzed using chi-square statistics, which involves no assumptions about the form of the original distributions from which the observations came. The chi-square statistics requires that the data be cast in nominal form into mutually exclusive and 
exhaustive categories. The conventional and traditional 0.05 level was set as the significance level for hypothesis testing.

\section{RELIABILITY}

Myers, McCaulley, Quenk and Hammer (1998) addressed the internal consistency and reliability of the MBTI, particularly the Form M. In 1996, based on a national sample of about 3,000 adults, they used two techniques for determining internal consistency reliability. First, was the "split-half reliability" where the item pool is split into two halves that are assumed to be equivalent. The scores from the two parts are then correlated. In addition, the internal consistency of the four MBTI scales was also estimated using coefficient alpha (also callęd Cronbach's alpha), which is the average of all the item correlations. To account for replicability of results, they included continuous score reliability estimates for the four preference scales to show the ability of the instrument to consistently report the same type.

An assumption derived from their observations was that respondents having "a good command of perception or judgment (i.e., with good type development) are more likely to be clear about their own preferences" and "they therefore will report their preferences more consistently " (Myers et al, p. 160). They contend that the quality of perception and judgment appears to be related to an individual's achievement level. Respondents with higher achievement levels will report their preferences more consistently, thus these samples will demonstrate higher reliabilities than samples from lesser achieving respondents.

Validity

Instrument validity is based on the MBTI's ability to show relationships and outcomes predicted by Carl Jung's theory of psychological type. Myers (1962) states that

in-so-far as the type preferences are found to correlate, in appropriate directions, with interests, values and needs ascertained by other tests, or to correlate approximately with any other external evidence of internal differences, support is afforded for the validity of the theory and the Indicator (p. 21).

Myers et al. (1998) examined two kinds of evidence for the validity of the MBTI: 1) evidence for the validity of the four preference scales and 2) evidence for the validity of whole types. Numerous instruments show a correlation between the four preference scales and provide support for the predictions of type theory. Some of the instruments mentioned include the Minnesota Multiphasic Personality Inventory (MMPI), the Leadership Style Indicator (LSI), the California Psychological Inventory (CPI), the StrongCampbell Interest Inventory (SCII), and the Edwards Personality Preference Schedule (EPPS).

\section{FINDINGS OF THE STUDY}

Based on the statistical findings (Tables I through III), the responses of students support the null hypothesis that there is no significant difference between the business and aviation students on focusing attention, information taking, and decision making preference indicators. However, Table IV reveals that there is a significant difference between business and aviation students in the way they orient themselves to the environment (Judging/Perceiving).

Teaching/Learning Implications and Recommendations

As shown in the Appendix, Tables I-IV, the findings of this study suggest that aviation students only show significant difference from business students in their orientations to the outer world (the Judging (J) and (P) scale). They show a significant preference for the Perceiving attitude. People who show preferences for the Perceiving attitude are more attuned to incoming information. They seem in their outer behavior to be spontaneous, curious, adaptable, and open to what is new or changeable. They want to receive information as long as possible in an effort to miss nothing that is important. (Briggs-Myers, et. al., p.27).

Tieger and Barron-Tieger (2001) describe Perceivers as being happiest when leaving their options open, changing goals as new information is available, and they like adapting to new situations. They concentrate on how projects are completed, as opposed to an emphasis on completing the task. Their satisfaction comes from starting projects rather than finishing them. They are not oriented toward deadlines, viewing them as elastic. They tend to have a "play ethic" that suggests playing now and finishing the job later.

On the other hand, Judgers learn best when they know what the goals are and that an outline is being followed...all of which impedes the learning process for Perceivers. (Kroeger and Thuesen, 1988, p. 185).

It is important that faculty are alert to the emotional and mental burdens placed on students who are forced to follow an instructor who is tapping only his/her auxiliary style rather than dominant style. Learning new course material is sometimes stressful especially when learning it in an auxiliary style. For example, the majority of business students may need the structured environment of an outline and definite goals to be completed in a given class period while a class of aviation students who are predominantly Perceivers could be frustrated by those goals if their ability to engage in vigorous class discussion about the issue is limited.

It would follow logically that students of aviation be provided an information-rich learning environment in which they can satisfy their intellectual curiosity about their chosen fields. Aviation students would tend to be more attuned to the latest developments in the field of aviation than would business students in the field of business. It is also logical that aviation students might well be given ample room for play as well as work. They would appreciate the opportunity for fun in the classroom. Teachers should recognize that these students would not be strongly oriented toward 
meeting deadlines, and teachers should be attentive to the appropriate strategies for dealing with deadlines.

Other implications for teachers of aviation students would include expanding classroom learning well beyond a single textbook and a single syllabus designed to meet specific goals. It does not mean, however, that all students of aviation will be Perceivers but that the stronger mix of predominantly Perceiving styles in the classroom will necessitate that opportunities for discussion, fun, skill practice, research, and problem-solving activities be built into the learning activities in order to accommodate both styles. It is also important to recognize that there are implications for teachers whose types are not congruent with those of their students. A Judging teacher generally prefers to follow a schedule and maintain order in the classroom. A Perceiving teacher encourages discussion, movement, social activities, and participation by students in decision-making. An aviation teacher whose preference is Judging may be operating outside his/her own comfort level in that Judging requires a structured, goal-oriented teaching environment. It may be quite stressful for a Judger to offer opportunities for extended discussion in order to address the Perceiving style of aviation learners while trying to be sure the material is covered in a timely manner. That being the case, should one attempt to match teachers of one type with students of the same type? The 1998 MBTI Manual references a series of studies pertaining to matching teachers with learners by MBTI profiles, most of which were inconsistent in their findings. They referenced other studies where teachers attempted to match their style of teaching with the needs of the learner. The findings of those studies seemed to indicate that matching by type does not guarantee learner satisfaction or successful outcomes.

The implication for teachers is that students at times need the natural support obtained from a teacher who speaks the same language and at other times may benefit from the challenge of a different type (Myers, McCaulley, Quent \& Hammer, 1998, p. 266). It is imperative that a healthy balance of Judging/Perceiving activities be utilized in the classroom so that neither style is operating at all times in their auxiliary teaching/learning mode. MBTI research encourages both teachers and students to approach interactions consistent with their own personal style followed by attention to the different needs of others (Myers, McCaulley, Quenk \& Hammer). +

Mary Kutz is an assistant professor in the College of Education, Aviation and Space Education, Oklahoma State University, Stillwater, Oklahoma. She holds a Doctor of Education degree in Applied Education Studies, Aviation and Space Education, Oklahoma State University, as well as Master of Business Administration and Bachelor of Business Administration degrees from the University of Central Oklahoma. Her aviation management and leadership experience includes 20 years with the Federal Aviation Administration.

David B. Carmichael is an associate professor of management at Oklahoma State University. He holds a BBA degree in Personnel and Industrial Relations from the University of North Texas, a MBA with high honors from Oklahoma City University, and a Ph.D. in Adult and Higher Education from the University of Oklahoma. His experience includes 32 years with the Federal Aviation Administration.

Mahmood Shandiz is currently the Senior Associate Dean of the Meinders School of Business and Professional Management Science at Oklahoma City University. He is also a senior consultant at the B.D. Eddie Business Research and Consulting Center at Oklahoma City University. His business and industry experience includes six years as regional sales director at General Nutrition Corporation. In addition, he has extensive international teaching experience and is widely published.

Dovie Brown is a member of the adjunct faculty in the College of Education, Aviation and Space Education, Oklahoma State University, Stillwater, Oklahoma. She holds a Masters of Science in Natural and Applied Sciences, aviation and space option, from Oklahoma State University and a Bachelor of Business Administration degree from the University of Central Oklahoma and is currently completing coursework toward a doctorate in Occupational Education and Oklahoma State University. Her experience includes 23 years with the Department of Defense (DOD). 


\section{REFERENCES}

Briggs-Myers, I., McCauley, M., Quenk, N. \& Hammer, A. (1998). A guide to the development and use of the Myers-Briggs type indicator. Palo Alto, CA: Consulting Psychologists Press, Inc.

Carland, J. \& Carland, J. (1987). An investigation into the distinctions between cognitive styles of business and non-business students. Journal of Education for Business. 63, 68-71.

Felder, R. (1989). Meet your students: 1. Stan and Nathan. Chemical Engineering Education, 78, 674-681.

Felder, R, \& Silverman, L. (1988). Learning and teaching styles in engineering education. Engineering Education. 78, 674681 .

Kroeger, O. \& Thuesen, J. (1993). Type talk at work, how the 16 personality types determine your success on the job. NY: Dell Publishing.

Lawrence, Gordon D. (1998). Description of the sixteen types. Gainesville, FL: Center for Application of Psychological Types.

McCaulley, M. (1976). Psychological types in engineering: implications for teaching. Engineering Education, 66, 729-736.

McCaulley, M. Godleski, E. Harrisberger, L., Sloan, E., \& Yokomoto, C. (1983). Applications of psychological type in engineering education. Engineering Education, 73, 301-307.

McCaulley, M. (1990). The MBTl and individual pathways in engineering design. Engineering Education, 80, 537-542.

Mitchell, W. (1976). A report on the feasibility and design of a longitudinal tracking system for evaluating the effects of medical student preceptorships on career development processes and dispositions. Rolling Meadows, IL: American Medical Students Association Foundation.

Myers, 1. B. (1962). The Myers-Briggs type indicator. Palo Alto, CA: Consulting Psychologists Press.

Myers, I.B., McCaulley, M.H., Quenk, N.L. \& Hammer, A.L. (1998). MBTI Manual, A Guide to the Development and Use of the Myers-Briggs Type Indicator. Palo Algo, CA: Consulting Psychologists Press.

Rodman, S., \& Dean, R. (1985). Teaching engineers: Is there a better way? Engineering Education, 75, 288-291.

Schroeder, C. (1993). New students-New learning styles. Change, 25, 21-26.

Shank, M. \& Langmeyer, L. 1994. Does personality influence brand image? The Journal of Psychology, 128, 157-164.

Simon, L. (1978). Predictors of achievement in clinical pharmacy course. American Journal of Pharmaceutical Education, 42, 111-114.

Thomas E.L. Jr. (1998). A comparative study of 1975 and 1993 entering Freshman engineering students at Auburn University using the Myers Briggs Type Indicator. Unpublished doctoral dissertation.

Tieger, Paul D., and Barron-Tieger, Barbara (2001). Do what you are: Discover the perfect career for you through the secrets of personality type, $3^{\text {rt }}$ Edition. Boston: Little, Brown and Company.

Wicklein, R. \& Rojewski, J. (1995). The relationship between psychological type and professional orientation among technology education teachers. Journal of Technology Education, 7. 


\section{APPENDIX}

Table I Relation Between Students' Major and MBTI-Focusing Attention Indicator

\begin{tabular}{|l|c|c|c|}
\hline Major/EI & Extraversion & Introversion & Total \\
\hline Business & 93 & 74 & 167 \\
\hline Aviation & 65 & 53 & 118 \\
\hline Total & 158 & 127 & 285 \\
\hline
\end{tabular}

$X^{2}=.0102, \mathrm{df}=1, \mathrm{p}=.92, \alpha=.05, X^{2}$-critical value $=3.84$

Since $p>.05 \mathrm{H}_{0}$ is not rejected.

Table II Relation Between Students' Major and

MBTI-Information Taking Indicator

\begin{tabular}{|l|c|c|c|}
\hline Major/NS & Intuition & Sensing & Total \\
\hline Business & 89 & 78 & 167 \\
\hline Aviation & 52 & 66 & 118 \\
\hline Total & 141 & 144 & 285 \\
\hline
\end{tabular}

$\mathrm{X}^{2}=2.35, \mathrm{df}=1, \mathrm{p}=.12, \alpha=.05, \mathrm{X}^{2}$-critical value $=3.84$

Since $p>05 \mathrm{H}_{0}$ is not rejected.

Table III Relation Between Students' Major and MBTI-Decision Making Preference Indicator

\begin{tabular}{|l|c|c|c|}
\hline Major/FT & Feeling & Thinking & Total \\
\hline Business & 66 & 101 & 167 \\
\hline Aviation & 46 & 72 & 118 \\
\hline Total & 112 & 173 & 285 \\
\hline
\end{tabular}

$\mathrm{X}^{2}=0.008, \mathrm{df}=1, \mathrm{p}=.93, \alpha=.05, \mathrm{X}^{2}$-critical value $=3.84$

Since $p>05 \mathrm{H}_{0}$ is not rejected.

Table IV Relation Between Students' Major and

MBTI-Environmental Orientation Indicator

\begin{tabular}{|l|c|c|c|}
\hline Major/JP & Judging & Perceiving & Total \\
\hline Business & 102 & 65 & 167 \\
\hline Aviation & 54 & 64 & 118 \\
\hline Total & 156 & 129 & 285 \\
\hline
\end{tabular}

$\mathrm{X}^{2}=6.55, \mathrm{df}=1, \mathrm{p}=.011, \alpha=.05, \mathrm{X}^{2}$-critical value $=3.84$

Since $p<.05 \mathrm{H}_{0}$ is rejected. 
Journal of Aviation/Aerospace Education \& Research, Vol. 14, No. 1 [2004], Art. 1 